\title{
Pengaruh pendidikan gizi terhadap pengetahuan dan sikap tentang gizi anak Sekolah Dasar
}

\author{
Nuryanto $^{1}$, Adriyan Pramono ${ }^{1}$, Niken Puruhita ${ }^{1}$, Siti Fatimah Muis ${ }^{1}$
}

\begin{abstract}
Background: Nutrition education is one method to change the knowledge and attitude of nutrition on school children. Objective: The study aimed to see the effect of nutrition education on knowledge and attitude of nutrition among school children.

Methods: This was one group pre-post test design of a quasi-experimental design. Subjects were 99 school children randomly selected through multi stage sampling method among the $4^{\text {th }}, 5^{\text {th }}$, and $6^{\text {th }}$ graders. They were given nutrition education using posters and pocket books in children meeting for three months. The data of knowledge and attitude were collected through interview using structure questionnaires. The differences in knowledge attitude and practice of of nutrition among school children were tested by Wilcoxon test.

Results: The mean of knowledge about nutrition among school children before nutrition education is $66,45 \pm 9,6 \%$ increasing to $71,61 \pm 9,3 \%$ after nutrition education. Median of attitude before nutrition education is $70,31 \%$ increasing to $75 \%$ after nutrition education. The result showed that there was an effect of nutrition education on knowledge and attitude of school children.
\end{abstract}

Conclusion: Nutrition education can improve knowledge and attitude of school children.

Key words : nutrition education, knowledge, attitude, school children

\begin{abstract}
ABSTRAK
Latar belakang: Salah satu metode untuk meningkatkan pengetahuan dan sikap gizi pada anak sekolah yaitu pendidikan gizi. Tujuan: Tujuan penelitian ini untuk mengetahui pengaruh pendidikan gizi terhadap pengetahuan dan sikap tentang gizi pada anak sekolah.

Metode: Penelitian ini merupakan studi kuasi eksperimen dengan desain one group pre-post test. Jumlah subjek 99 anak sekolah yang di acak menurut tingkatan, kelas 4, kelas 5, dan kelas 6. Subjek tersebut diberikan pendidikan gizi menggunakan poster dan buku saku selama tiga (3) bulan. Data pengetahuan dan sikap diperoleh dengan wawancara menggunakan kuesioner ter-struktur. Perbedaan pengetahuan dan sikap serta praktek tentang gizi pada anak sekolah dianalisis dengan Uji Wilcoxon.

Hasil: Rata-rata pengetahuan gizi pada anak sekolah sebelum intervensi pendidikan gizi adalah 66,45 $\pm 9,6 \%$, meningkat menjadi 71,61 $99,3 \%$ setelah intervensi pendidikan gizi. Median sikap anak sekolah tentang gizi sebelum intervensi 70,31\% meningkat menjadi $73 \%$ setelah pendidikan gizi. Hasil tersebut menunjukkan bahwa pendidikan gizi meningkatkan pengetahuan dan sikap tentang gizi.

Simpulan: Pendidikan gizi meningkatkan pengetahuan dan sikap gizi anak sekolah
\end{abstract}

Kata kunci: pendidikan gizi, pengetahuan, sikap, anak sekolah

\section{PENDAHULUAN}

Usia sekolah (usia 5 sampai 14 tahun), merupakan salah satu masa yang mengalami tumbuh kembang yang cepat. Pada usia ini aktifitas fisik terus meningkat seperti, bermain, berolah raga atau membantu orang tua dalam bekerja. Asupan gizi yang baik dari segi kuantitas maupun kualitas diperlukan agar tumbuh kembang anak dapat optimal. Pemberian gizi pada usia ini biasanya tidak berjalan secara sempurna, karena banyak faktor lingkungan sangat mempengaruhi perilaku makanannya. ${ }^{1,2,3}$

Kebiasaan makan yang salah pada anak sekolah dapat mengakibatkan masalah gizi yang serius, seperti

${ }^{1}$ Jurusan Ilmu Gizi Fakultas Kedokteran Universitas Diponegoro obesitas bagi mereka yang kelebihan kalori atau gizi kurang dan stunted bagi mereka yang kekurangan gizi. Prevalensi anak pendek dan gizi kurang pada anak sekolah secara internasional masih tinggi. Dilaporkan oleh Jukes 2008, bahwa prevalensi anak sekolah yang pendek sekitar 48-56\%, sedangkan prevalensi gizi kurang sekitar 34-62\%. Hasil Riset Kesehatan Dasar menunjukkan hasil bahwa secara nasional prevalensi kurus adalah $13,3 \%$ pada laki-laki dan $10,9 \%$ pada perempuan. Sedangkan prevalensi BB lebih pada lakilaki $9,5 \%$ dan perempuan $6,4 \% .^{4}$

Gambaran dan perhatian tentang kesehatan dan gizi pada anak sekolah merupakan isu yang sangat penting. Masalah gizi pada anak sekolah ini sering dikaitkan dengan pola konsumsi kebiasaan makan dan perilaku baik dirumah maupun di sekolah. Perilaku makan seperti, konsumsi makanan jajanan, junk food 
atau street food dari nilai gizi banyak mengandung lemak, terutama makanan jajanan yang di goreng ini sering terjadi. Selain itu makanan jajanan juga tidak mengenyangkan. Mungkin hal inilah yang dapat dikaitkan dengan terjadinya obesitas pada anak-anak sekolah. ${ }^{1,5}$

Salah satu faktor yang mempengaruhi gizi seseorang adalah kurangnya pengetahuan tentang gizi. Berkurangnya pengetahuan tersebut juga akan mengurangi kemampuan seseorang untuk menerapkan informasi gizi dalam kehidupan sehari-hari. Salah satu cara untuk meningkatka pengetahuan seseoarang yaitu dengan cara memberikan pendidikan gizi sedini mungkin. Pendidikan gizi ini dapat diberikan melalui penyuluhan, pemberian poster, leaflet atau booklet pada anak sekolah. ${ }^{6,7}$

Pendidikan dapat meningkatkan pengetahuan seseorang, dengan adanya peningkatan pengetahuan maka diharapkan akan terjadi perubahan perilaku yang lebih baik terhadap gizi dan kesehatan. ${ }^{7}$ Program pendidikan kesehatan dan gizi pada anak sekolah merupakan salah satu cara untuk menerapkan intervensi kesehatan global secara sederhana dan efektif untuk memperoleh pendidikan yang labih luas. $^{1}$

Menurut Healthy People 2010, Pendidikan gizi akan meningkatkan pengetahuan gizi anak dan akan membantu sikap anak yang dapat mempengaruhi kebiasaan anak dalam memilih makanan dan snack yang menyehatkan. Pengaruh pendidikan gizi terhadap kesehatan mungkin akan lebih efektif jika targetnya adalah langsung pada anak usia sekolah. ${ }^{8}$

Mengacu dari faktor tersebut, maka masalah yang disajikan adalah " apakah ada pengaruh pendidikan gizi terhadap pengetahuan dan sikap tengtang gizi pada anak sekolah Dasar". Penelitian ini bertujuan untuk mengetahu pengaruh pengaruh pendidikan gizi terhadap pengetahuan dan sikap tengtang gizi pada anak sekolah Dasar.

\section{METODE DAN BAHAN}

Desain penelitian yang digunakan adalah penelitian quasi experimental dengan rancangan nonrandomized one group pre-post test design.. Penelitian dilakukan di 2 SD di Semarang, yaitu SDN 05 Pandean Lamper Kecamatan Semarang Tengah dan SDN 01 Tembalang Kecamatan Tembalang Kota Semarang, dengan pertimbangan banyak ditemukan penjaja makanan di kedua SD tersebut. Sekolah Dasar Negeri 01 Tembalang dianggap mewakili daerah pinggir kota dan SDN 05 Pandean Lamper dianggap mewakili tengah Kota.

Subjek dalam penelitian adalah anak SD kelas 4, 5 dan 6, dipilih karena anak pada usia tersebut mudah diajak untuk berkomunikasi. Pengambilan sampel dilakukan menggunakan multistage random sampling, langkah pertama adalah memilih 2 SD di daerah tersebut. Selanjutnya dari sekolah yang terpilih dipilih 99 siswa kelas 4, 5 dan 6 secara acak. Intervensi dilakukan dengan pendekatan KIE mengenai Gizi Seimbang pada Anak Sekolah, dalam bentuk buku saku, poster gizi seimbang dan penyuluhan kelompok kepada anak SD serta memberikan buku gizi seimbang kepada orang tua. Pengetahuan Anak tentang Gizi merupakan Jumlah jawaban yang benar tentang pengetahuan gizi seimbang pada anak sekolah. Pengetahuan didapatkan dari wawancara menggunakan kuesioner terstruktur, baik sebelum dan setelah pendidikan gizi. Sikap Anak tentang Gizi merupakan Jumlah jawaban yang benar tentang gizi seimbang pada anak sekolah. Sikap gizi seimbang didapatkan dari wawancara menggunakan kuesioner terstruktur, baik sebelum dan setelah pendidikan gizi. Data dianalisis dengan uji paired t-test dan wilcoxon.

\section{HASIL}

\section{Karakteristik Subjek}

Karakteristik subjek dan orang tua mereka dapat dilihat pada tabel 1 . Tabel 1 menunjukkan bahwa $46,5 \%$ subjek berjenis kelamin perempuan dengan rerata umur mereka sebesar $10,7 \pm 1,1$ tahun. Pendidikan terakhir yang ditamatkan oleh orang tua mereka (Ibu) tertinggi 35,3\% tamat SD dan 28,3\% tamat Sekolah Menengah Atas (SMA).

\section{Pengaruh Pendidikan Gizi Terhadap Pengetahuan Gizi Anak Sekolah Dasar}

Hasil penelitian tentang pengaruh pendidikan gizi terhadap pengatahuan anak terlihat dalam Tabel 2 .

Tabel 2 didapatkan hasil bahawa ada perbedaan rerata persen pengetahuan gizi anak SD antara sebelum dengan setelah pendidikan gizi $(\mathrm{p}=0,0001)$. Dimana rerata pengetahuan gizi sebelum diberi pendidikan gizi sebesar $66,46 \pm 9,6 \%$ naik menjadi $71,61 \pm 9,3 \%$.

\section{Pengaruh Pendidikan Gizi Terhadap Sikap Tentang Gizi Anak Sekolah Dasar}

Hasil penelitian tentang pengaruh pendidikan gizi terhadap sikap anak tentang gizi terlihat dalam tabel 3 . Tabel 3 menunjukkan bahwa ada perbedaan median persen sikap gizi anak SD antara sebelum dengan setelah pendidikan gizi. Dimana median sikap tentang gizi sebelum pendidikan gizi sebesar 70,3\%1 naik menjadi $75 \%$ setelah pendidikan gizi. 
Tabel 1. Karakteristik subjek dan ibu

\begin{tabular}{lcc}
\hline \multicolumn{1}{c}{ Karakteristik } & Jumlah & Persentase (\%) \\
\hline Jenis Kelamin & & \\
Laki-laki & 46 & 46,5 \\
Perempuan & 53 & 53,5 \\
\hline Total & 99 & 100,0 \\
\hline Pendidikan terakhir yang ditamatkan Ibu & & \\
tidak sekolah & 8 & 8,1 \\
Tamat SD & 35 & 35,3 \\
tamat SLTP & 20 & 20.2 \\
tamat SMA & 28 & 28.3 \\
Diploma 1 2 3 & 4 & 4 \\
S1 & 4 & 4 \\
\hline Total & 99 & 100,0 \\
\hline
\end{tabular}

Tabel 2. Rerata Pengetahuan Gizi Anak SD Sebelum dan Setelah Pendidikan

\begin{tabular}{lcccc}
\hline \multicolumn{1}{c}{ Pengetahuan Gizi } & Sebelum & Setelah & Delta & $\mathrm{p}$ \\
\hline Rerata (\%) & 66,46 & 71,61 & 5,16 & \multirow{2}{*}{$0,0001^{\text {a }}$} \\
Simpang Baku & 9,6 & 9,3 & 11,3 & \\
\hline $\mathrm{n}$ & 99 & 99 & 99 & \\
\hline
\end{tabular}

${ }^{a}$ Paired t-test

Tabel 3. Deskripsi sikap sebelum dan setelah pendidikan gizi

\begin{tabular}{ccccc}
\hline \multirow{2}{*}{ Sikap Tentang Gizi } & \multicolumn{2}{c}{ Sikap } & \multirow{2}{*}{ Delta } & \multirow{2}{*}{$\mathrm{p}$} \\
\cline { 2 - 3 } & Sebelum & Setelah & & \multirow{2}{*}{3,13} \\
Median & 70,31 & 75,00 & & \\
Minimal & 56,25 & 53,12 & & \multirow{2}{*}{$0001^{\mathrm{b}}$} \\
Makimal & 87,50 & 87,50 & & \\
\hline $\mathrm{N}$ & 99 & 99 & 99 & \\
\hline
\end{tabular}

${ }^{\mathrm{b}}$ Wilcoxon Test

\section{PEMBAHASAN}

Hasil penelitiin menunjukkan bahwa ada pengaruh pendidikan gizi terhadap pengetahuan anak SD tentang gizi anak sekolah. Hasil ini sesuai dengan penelitian pada anak SD di New Jersey tentang program pendidikan sekolah untuk mempromosikan makanan yang sehat dan olah raga, hasil penelitian tersebut mendapatkan hasil bahwa terjadi peningkatan pengetahuan anak SD setelah mendapatkan program pendidikan. Program pendidikan diberikan dalam bentuk, poster, website dan pendidikan langsung ke anaknya. ${ }^{9}$

Hasil penelitian ini berbeda dengan penelitian pada anak SD di Irlandia yang diberi pendidikan gizi, dimana hasil penelitiannya menunjukkan bahwa tidak ada perbedaan yang signifikan tentang pengetahuan anak SD setelah mendapatkan pendidikan gizi selama 3 bulan baik pada kelompok intervensi maupun kelompok kontrol. Dijelaskan bahwa tidak adanya perbedaan yang signifikan dalam penelitian itu dkarenakan level pengetahuan gizi pada anak SD sebelum intervensi sudah tinggi. ${ }^{10}$

Pendidikan kesehatan didefinisikan sebagai upaya menerjemahkan apa yang telah diketahui tentang kesehatan ke dalam perilaku yang diinginkan dari perorangan ataupun masyarakat melalui proses pendidikan. Pendidikan gizi atau kesehatan dapat dilakukan dengan cara penyuluhan maupun dengan cara lain seperti pemberian poster. Untuk merubah perilaku konsumsi makanan jajanan mungkin yang paling berkaitan adalah dengan memberikan pendidikan kesehatan dan gizi. karena dengan adanya pendidikan kesehatan, sesuai dengan batasan WHO (1954), pendidikan kesehatan dapat mengubah perilaku orang atau masyarakat dari perilaku yang tidak sehat menjadi perilaku yang sehat. Dalam hal ini 
mencakup perilaku pemilihan makan makanan yang baik dan menyehatkan. ${ }^{7}$

Penyuluhan merupakan salah satu cara untuk meningkatkan pengetahuan gizi seseorang. Karena penyuluhan merupakan sarana edukatif untuk meningkatkan pengetahuan seseorang. Tujuan akhir penyuluhan adalah adanya perubahan perilaku manusia yang dilakukan secara edukatif. Karena dengan adanya penyuluhan diharapkan orang bisa memahami pentingnya makanan dan gizi, sehingga mau bersikap dan bertindak mengikuti norma-norma gizi. Pendidikan dan pengetahauan merupakan faktor tidak langsung yang mempengaruhi perilaku seseorang. Pengetahuan yang didapat seseorang tidak terlepas dari pendidikan. Semakin tinggi pendidikan orang maka pengetahuan semakin luas. ${ }^{6,7}$

Kurangnya pengetahuan dan salah konsepsi tentang kebutuhan pangan dan nilai pangan adalah umum dijumpai setiap negara di dunia. Kemiskinan dan kekurangan persediaan pangan yang bergizi merupakan faktor penting dalam masalah gizi, namun selain itu gangguan gizi juga disebabkan oleh kurangnya pengetahuan tentang gizi atau kemampuan untuk menerapkan informasi tersebut dalam kehidupan sehari-hari. ${ }^{6}$

Tujuan dari pendidikan gizi berdasarkan pendekatan sebaran informasi cukup sederhana yaitu memberikan informasi yang masyarakat butuhkan tentang makanan dan zat-zat gizi yang mereka perlukan dan bagaimana makan yang baik. Masyarakat dipandang sebagai orang yang cerdas dan tidak perlu diberitahu apa yang harus dilakukan. Pendekatan ini bertolak belakang dengan pendekatan seorang professional di bidang gizi harus aktif melakukan promosi kesehatan. ${ }^{11}$

Hasil penelitiin menunjukkan bahwa ada pengaruh pendidikan gizi terhadap sikap anak SD tentang gizi anak sekolah.Hasil ini berbeda dengan penelitian yang dilakukan pada anak SD di Kota Semarang, yang mendapatkan pendidikan melalui komik. tentang makanan jajanan sehat dan bergizi untuk meningkatkan pengetahuan dan sikap anak SD, dimana penelitian itu didapatkan hasil bahwa tidak ada perubahan sikap dalam hal keragaman dan keamanan makanan jajanan. ${ }^{12}$

Adanya peningkatan sikap ini dimungkinkan juga oleh faktor orang tua, dimana penelitian ini didapatkan hasil bahwa $97 \%$ orang tua (Ibu) memberikan nasihat kepada anaknya pada saat anak akan berangkat sekolah. Nasehat yang sering diberikan ibu kepada anaknya diantaranya seperti "jangan jajan dipinggir jalan atau disembarang tempat", "jajan atau makan makanan yang sehat dan aman ya". Orang tua dapat memberikan masukan atau contoh yang baik pada anaknya, terutama dalam hal makanan anaknya maka orang tua dapat memperkenalkan makanan pada anak tentang apa, kapan dan dimana kita makan. ${ }^{13}$

Sangat sulit untuk memberikan masukan kepada anak kita agar menjaga makanannya, anak-anak lebih menyukai makanan yang populer dimata mereka seperti, keripik dan minuman ringan bergula. Orang tua dan anak dapat bekerjasama dengan memakai bahasa dan konsep yang cocok untuk usia mereka. Mereka dapat berkompromi dan berkomunikasi tentang gizi dan kesehatan. Salah satu strategi orang tua yaitu dengan mempertimbangkan hal-hal yang populer juga, seperti dengan cara memberikan contoh seoarang atlet atau intertainer yang sedang mengikuti diets. selain itu anak mungkin juga diperlihatkan dalam pemilihan makanan keluarga. Sehingga dengan hal itu orang tua secara langsung dapat memberikan contoh, pesan dan image yang baik untuk anakanaknya. ${ }^{14}$

Meningkatnya sikap anak tentang gizi mungkin juga disebabkan oleh meningkatnya pengetahuan anak. Meningkatnya pengetahuan gizi pada anak melalui pendidikan gizi akan membantu sikap anak dan akan mempengaruhi kebiasaan anak dalam memilih makanan dan snack yang menyehatkan. ${ }^{8}$

Sikap merupakan reaksi atau respons yang masih tertutup dari sesorang terhadap suatu stimulus atau objek. sikap belum merupakan tindakan atau aktivitas, akan tetapi merupakan predisposisi tindakan suatu perilaku. Dalam penentuan sikap ini pengetahuan keyakinan dan keyakinan berpengaruh besar terhadap sikap sesorang, termasuk dalam hal menyikapi pendidikan gizi yang di berikan. ${ }^{15}$

\section{SIMPULAN}

Pendidikan Gizi dapat meningkatkan pengetahuan dan sikap tentang gizi anak Sekolah Dasar.

\section{DAFTAR PUSTAKA}

1. Jukes $\mathrm{MCH}$, Drake LJ dan Bundy DAP 2008 School Health, Nutrition and Education For All Levelling the Playing Field. CABI Internasional. USA. p. 3-29

2. Mahan LK, Escott-Stump S 2008 Krause's Food \& Nutrition Therapy. $12^{\text {th }}$ edition. Saunders Elsevier. p.234 - 236

3. Sediaoetama DA 2004 Ilmu Gizi untuk Mahasiswa dan Profesi. Jilid 1. Dian Rakyat. Jakarta

4. Departemen Kesehatan RI 2008 Riset Kesehatan Dasar 2007. Badan Penelitian dan Pengembangan Kesehatan. Depkes RI. Jakarta. 
5. Judarwanto, W. 2006, Antisipasi Perilaku Makan Anak Sekolah http://www.pdpersi. co.id/ pdpersi/news/artikel.

6. Suhardjo 2003 Berbagai Cara Pendidikan Gizi. Bumi Aksara, Jakarta.

7. Machfoedz I dan Suryani S 2007 Pendidikan Kesehatan bagian dari Promosi Kesehatan, Fitramaya, Yogyakarta, p.8-73

8. Healthy People 2010 Volume II. Department of Health and Human Services. 2000. Healthy People 2010. 2nd ed. With Understanding and Improving Health and Objectives for Improving Health. 2 vols. Washington, DC: U.S.Government Printing Office.

9. Jan S, Bellman C, Barone J, Jessen L, Arnold M 2009 Shape It Up: A School-Based Education Program to Promote Healthy Eating and Exercise Developed by a Health Plan in Collaboration With a College of Pharmacy. Journal of Managed care Pharmacy. Vol.15 No.5. USA

10. Friel S, Kelleher C, Campell P, Nolan G 1999 Evaluation of the Nutrition Education at Primary
School (NEAPS) Programme. Public Health Nutr. 2(4): 549-55.

11. Contento IR 2006 Nutrition Education Linking Research Teory $\mathrm{n}$ practice. Johnes\&Barletts Publishers, Sudbury. P.1-21

12. Widajanti L, Suryawati C, Sugihantono A 2009 Pengaruh Komik Makanan Jajanan Sehat dan Bergizi Untuk Meningkatkan Pengetahuan dan Sikap Anak Sekolah Dasar. Airlangga University Press. The Indonesian Journal of Publich Health, UNAIR, Surabaya. p.19-23

13. Shield J, Nullen MC 2002 The American Dietetic Association Guide to Healthy Eathing For Kids. How Your Children Can Eat Smart From Five Twelve. John Wiley \& Sons. Inc. USA.. P.10-15, 49-53

14. Thompson J, Manore M 2010 Nutritional an Applied Approach. Second Edition.. Pearson Benjamin Cummings. p.528-569, 651

15. Notoatmodjo S 2007 Promosi Kesehatan dan Ilmu Perilaku, Rineka Cipta, Jakarta, p.10-150 